\title{
Prevalence of NCD Risk Factors Among the Adult Family Members of Students of School (Phase - A)
}

\author{
Ratindra Nath Mondal, ${ }^{1}$ Anupom Das, ${ }^{1}$ Md. Foyzul Islam, ${ }^{2}$ Priyanka Podder, ${ }^{2}$ Soma Pramanik, ${ }^{1}$ Moni Rani ${ }^{3}$
}

\begin{abstract}
Background: Like other developing countries, in our country major causes of mortality is shifted from communicable to non-communicable diseases. NCD already disproportionately affect low and middle income countries, where nearly three quarters of NCD deaths (28 million) occur annually. Management of the existing NCD and upcoming NCD will be a great challenge for the developing countries like us. Therefore a strategy of prevention of NCD is very important.

Materials and methods: This was a community based prospective interventional study, carried out in Mornea high school and Alef Uddin Sarker high school of Rangpur sadar. In the first phase, from each school 100 students from different classes were selected randomly. Then adult family members of these students were surveyed to see the prevalence of NCD risk factors. In second phase (ongoing) school health education will be given in Mornea high school (randomly chosen) monthly basis for 12 months and the students will share these with their family members. On the other hand the other school's students will not provide any health education. One of the guardian from each family will chosen for confirmation of the sharing of information of school health education acquired by students over phone after each class. After one year prevalence of NCD risk factors will be surveyed again to know whether there are any significant differences of outcome of school health education.
\end{abstract}

Results: In this study we have been able to study of 356 adult people of both sexes. From the Mornea high school 197 (55.3\%) and Alef Uddin Sarker high school 159 (44.7\%). Mean age of the study population was 47.33 years and female was more than male $66.3 \%$. Awareness of NCD was found in only $10.4 \%$ of the study population. Overall $96.63 \%$ had NCD risk factors, $30.90 \%$ had two risk factors and $50.26 \%$ had 3 or more risk factors. Overall prevalence of smoking was $36.8 \%$, among them $20.5 \%$ were current smoker. $33.1 \%$ of the study population used to take smokeless tobacco. Among the survey population only $14.3 \%$ used to take vegetables 7 days/week. $32.6 \%$ (I I6) people were physically inactive and $6.7 \%$ (24) had sedentary lifestyle. Only $5.3 \%$ of the people were obese and $66.57 \%$ had central obesity. Prevalence of hypertension and diabetes among the study population was $28.9 \%$ and $4.77 \%$ respectively. Among the known hypertensive $72.7 \%$ (16) used to take antihypertensive drug regularly and blood pressure was controlled in only $27.3 \%$. Among the known diabetic mean duration were 4.12 years and $62.5 \%$ (5) of the patients used to take the antidiabetic drug regularly.

Conclusions: In our study, awareness of NCD is very low but high prevalence of NCD risk factors, which are modifiable. So, an appropriate intervention is needed to modify the risk factors and thus prevention of NCDs.

Keywords: Non-communicable diseases (NCDs), school health education, risk factors

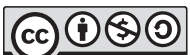

(cc) $\mathrm{BY}$ NC SA

DOI: https://doi.org/l0.3329/jom.v2 lil.44094

Copyright: (C) 2020 Mondal RN et al. This is an open access article published under the Creative Commons Attribution-NonCommercial-NoDerivatives 4.0 International License, which permits use, distribution and reproduction in any medium, provided the original work is properly cited, is not changed in any way and it is not used for commercial purposes.

Received: 04 June, 2018

Accepted: 07 December, 2018

1. Rangpur Community Medical College

2. TMSS Medical College

3. Rajshahi Medical College Hospital

Corresponding author: Dr. Ratindra Nath Mondal, Associate Professor of Medicine, Hypertension and Research center, Rangpur, Rangpur Community Medical College, Rangpur, Bangladesh.Email: dr.ratinmondal@gmail.com.

\section{Introduction:}

Non-communicable diseases (NCDs), also known as chronic diseases, are not passed from person to person. They are of long duration and generally slow progression. The 4 main types of non-communicable diseases are cardiovascular diseases (like heart attacks and stroke), cancers, chronic respiratory diseases (such as chronic obstructive pulmonary 
disease and asthma) and diabetes. Tobacco use, physical inactivity, unhealthy diet and the harmful use of alcohol increase the risk of NCDs. ${ }^{1}$ These behaviors lead to four key metabolic/physiological changes that increase the risk of NCDs: raised blood pressure, overweight/obesity, hyperglycemia (high blood glucose levels) and hyperlipidemia (high levels of fat in the blood). In terms of attributable deaths, the leading metabolic risk factor globally is elevated blood pressure (to which $18 \%$ of global deaths are attributed $)^{2}$ followed by overweight and obesity and raised blood glucose. Low- and middle-income countries are witnessing the fastest rise in overweight young children. ${ }^{1}$ NCDs are already a major importance in developed countries and are rapidly becoming a major public health threat in the developing world. ${ }^{3}$ NCDs were estimated to have contributed to almost $60 \%$ of deaths in the world and among them about $80 \%$ occur in the developing countries. ${ }^{4}$ Like many other countries, Bangladesh has been experiencing an epidemiological transition from communicable disease to $\mathrm{NCDs}^{5}$ due to economic development and increased level of control and treatment of infectious diseases. ${ }^{6}$ Some $51 \%$ of deaths in Bangladesh are due to non-communicable diseases and other chronic health conditions. ${ }^{7}$ According to the mortality profile of Bangladesh, 2014 highest mortality from circulatory system disease $(33.20 \%)$, followed by certain conditions originating in the perinatal period $(15.93 \%)$, respiratory system disease $(13.90 \%)$, nervous system disease $(3.89 \%)$ and digestive system disease $(0.53 \%){ }^{8}$

Hospital based study in department of Medicine; Rangpur Medical College has shown that $81.57 \%$ of the death was due to NCDs. ${ }^{9}$ An important way to reduce NCDs is to focus on lessening the risk factors associated with these diseases. Low-cost solutions exist to reduce the common modifiable risk factors (mainly tobacco use, unhealthy diet and physical inactivity, and the harmful use of alcohol) and map the epidemic of NCDs and their risk factors. ${ }^{1}$ This study was carried out to find out a low cost, easily affordable solution to reduce NCD risk factors and ultimately the development of NCD.

\section{Materials \& methods:}

This was a community based prospective interventional study, was carried out in Mornea high school and Alef Uddin Sarker high school of Rangpur district. Prior to start the study, we have taken permission from the divisional director of health, Rangpur and divisional education officer, Rangpur. Assuming unknown prevalence of NCD risk factors in adult population of Rangpur division a sample size of 385 was calculated to give the true prevalence with a precision of $5 \%$ with $95 \%$ confidence level. But due to economical constraints
100 students will be taken from each school and adult population of these students's family were studied. Random sampling method was used. From the 8 upazillas of Rangpur district, Ganggasara and Kaunia were selected by simple random sampling. Then from the list of secondary high school of the Ganggasara upazilla Mornea high school and from Kaunia upazilla Alef Uddin Sarker high school were selected for our study. 100 students were taken by random sampling from each school. Then adult family members of these students were surveyed to see the prevalence of NCD risk factors. At present we are taking lecture on non communicable diseases, its risk factors, preventive methods and possible complications of NCDs among these 100 students of Mornea high school. On the other hand the Alef Uddin Sarker high school's students will not provide any health education. One of the guardian from each family will chosen for confirmation of the sharing of information of school health education acquired by students over phone after each class. After one year prevalence of NCD risk factors will be surveyed again to know whether there are any significant differences of outcome of school health education.

\section{Measurement of blood pressure:}

Data collection and measurement of blood pressure was done by a non-medical stuff (trained for 7 days prior to start collection of data). During the course of the interview, the stuff made two measurements of blood pressure on each participant with a validated aneroid sphygmomanometer using a standardized technique. Study participants were instructed to refrain from drinking any caffeinated beverage, smoking half-hour preceding the interview. Both blood pressure measurements were obtained after the subject rested for at least $5 \mathrm{~min}$ in a seated position. In cases where the two readings differed by over $10 \mathrm{~mm}$ of $\mathrm{Hg}$, the stuff obtained two more reading, and the four measurements were averaged to classify blood pressure. Hypertension was defined on the basis of Joint National Committee (JNC) VII criteria. If average blood pressure remains $\geq 140 / 90 \mathrm{~mm} \mathrm{Hg}$, the person was labeled to have hypertension. Persons having systolic BP between 120-139 mm Hg and / or diastolic BP between 80$89 \mathrm{~mm} \mathrm{Hg}$ was labeled as pre-hypertension.

\section{Measurement of anthropometry:}

Body weight was measured (to the nearest $0.5 \mathrm{~kg}$ ) with the subject standing motionless on the weighing scale, feet about $15 \mathrm{~cm}$ apart, and weight equally distributed on each leg. Subjects were instructed to wear minimum outerwear (as culturally appropriate) and no footwear while their weight was measured. Height was measured (to the nearest $0.5 \mathrm{~cm}$ ) with the subject in an erect position against a vertical surface, and with the head positioned so that the top of the external 
auditory meatus leveled with the inferior margin of the bony orbit. Body mass index (BMI) was calculated by dividing body weight in kilogram by square of height in meter.

\section{Blood glucose test:}

Blood glucose was tested by glucometer. The people who is taking the antidiabetic drug/insulin currently and random blood glucose $\geq 11.1 \mathrm{mmol} / 1$ labeled as diabetes mellitus.

\section{Smoker:}

Those who currently smoke or have smoked tobacco in any form (cigarette, birri etc.) in last 6 months.

\section{Ex-smoker:}

Ex-smoker who gave up smoking at least 6 months before.

\section{Smokeless Tobacco (SLT):}

SLT are raw tobacco leafs taken other than inhalation route (usually taken with betel nut or use in inner aspect of lower lip).

\section{Obesity:}

BMI level $\geq 30 \mathrm{Kg} / \mathrm{M}^{2}$ (according to WHO).

\section{Central obesity:}

The absolute waist circumference $>102$ centimeters in men and $>88$ centimetres in women and the waist-hip ratio $>0.9$ for men and $>0.85$ for women.

\section{Methods of data collection:}

Initially, an appointed research assistant (non-medical) briefed about the objectives, benefits, risks and burdens of this study to the individual family member of the student. Only positive respondents were selected as research participant consistent with the selection criteria. A written informed consent was taken from each of the selected subject. The study did not involve any social, mental or physical risk to the patients.

\section{Statistical analysis:}

The interested variables was processed, edited and analyzed by SPSS windows version 17.0. The sociodemographic data of the study population were expressed in frequency distribution and their observed difference was tested by one sample ' $\mathrm{t}$ ' test and 'chisquare' test. $\mathrm{P}$ value $<0.05$ was considered as statistically significant with the $95 \%$ confidence interval.

\section{Results:}

In this study, out of 356 adult people of both sexes 197 $(55.3 \%)$ were from From the Mornea high school and 159 (44.7\%) from Alef Uddin Sarker high school. Mean age of the study population was 47.33 years and female was more than male $66.3 \%$ (Table I).

Table I: Socio-demographic characteristics of the study people of both school $(n=356)$

\begin{tabular}{|c|c|c|c|c|}
\hline \multicolumn{2}{|c|}{ Variables } & Mornea high school & Alef Uddin Sarker high school & Total \\
\hline \multicolumn{5}{|l|}{ Age } \\
\hline & Mean age (SD) & 48.11 years $( \pm 16.89)$ & 46.35 years $(14.80)$ & $47.33(16.003)$ \\
\hline & Age range & $18-110$ years & 20- 90 years & $18-110$ years \\
\hline \multirow[t]{2}{*}{ Sex } & Male & $73(37.1 \%)$ & $47(29.6 \%)$ & $120(33.7 \%)$ \\
\hline & Female & $124(62.9 \%)$ & $112(70.4 \%)$ & $236(66.3 \%)$ \\
\hline \multicolumn{5}{|c|}{ Level of education } \\
\hline & Illiterate & $111(56.3 \%)$ & $83(52.2 \%)$ & $194(54.5 \%)$ \\
\hline & 5 or less class & $51(25.9 \%)$ & $27(17 \%)$ & $78(21.9 \%)$ \\
\hline & $>5-10$ class & $26(13.2 \%)$ & $31(19.5 \%)$ & $57(16 \%)$ \\
\hline & $>10-12$ class & $6(3 \%)$ & $10(6.3 \%)$ & $16(4.5 \%)$ \\
\hline & Graduate and above & $3(1.5 \%)$ & $8(5 \%)$ & $11(3.1 \%)$ \\
\hline \multicolumn{5}{|c|}{ Occupation } \\
\hline & Housewife & $110(55.8 \%)$ & $102(64.2 \%)$ & $212(59.6 \%)$ \\
\hline & Agriculture & $61(31 \%)$ & $19(11.9 \%)$ & $80(22.5 \%)$ \\
\hline & Business & $5(2.5 \%)$ & $9(5.7 \%)$ & $14(3.9 \%)$ \\
\hline & Service & $2(1 \%)$ & $10(6.3 \%)$ & $12(3.4 \%)$ \\
\hline & Retired & $7(3.6 \%)$ & $4(2.5 \%)$ & $11(3.1 \%)$ \\
\hline & Others & $12(6.1 \%)$ & $15(9.4 \%)$ & $27(7.6 \%)$ \\
\hline \multicolumn{5}{|c|}{ Monthly income } \\
\hline & $<5000$ taka* & $166(84.3 \%)$ & $117(73.6 \%)$ & $283(79.5 \%)$ \\
\hline & 5001-10000 taka & $18(9.1 \%)$ & $23(14.5 \%)$ & $41(11.5 \%)$ \\
\hline & 10001-15000 taka & $9(4.6 \%)$ & $9(5.7 \%)$ & $18(5.1 \%)$ \\
\hline & $>15000$ taka & $4(2 \%)$ & $10(6.3 \%)$ & $14(3.9 \%)$ \\
\hline
\end{tabular}

*1 dollar $=82$ taka. 
Table II: Comparison of the NCD risk factors of the participant of both the schools

\begin{tabular}{lccc}
\hline Variable & $\begin{array}{c}\text { Mornea high school } \\
(\mathrm{n}=197)\end{array}$ & $\begin{array}{c}\text { Alef Uddin Sarker } \\
\text { high school }(\mathrm{n}=159)\end{array}$ & Total (n=356) \\
\hline Current smoking & $24.4 \%(48)$ & $15.7 \%(25)$ & $20.50 \%(73)$ \\
Smokeless tobacco & $38.6 \%(76)$ & $26.4 \%(42)$ & $33.1 \%(118)$ \\
Low vegetables intake (<4 days/week) & $65 \%(128)$ & $54.7 \%(87)$ & $60.4 \%(215)$ \\
Low physical activity & $32.5 \%(64)$ & $32.7 \%(52)$ & $32.6 \%(116)$ \\
Sedentary lifestyle & $7.6 \%(15)$ & $5.7 \%(9)$ & $6.7 \%(24)$ \\
Obesity & $4.6 \%(9)$ & $6.3(10)$ & $5.3 \%(19)$ \\
Central obesity & $66 \%(130)$ & $67.3 \%(107)$ & $66.57 \%(237)$ \\
Hypertension & $33 \%(65)$ & $23.9 \%(38)$ & $28.93 \%(103)$ \\
Diabetes mellitus & $3.04 \%(6)$ & $6.91 \%(11)$ & $4.77 \%(17)$ \\
\hline
\end{tabular}

Awareness of NCD was found in only $10.4 \%$ of the study population. Overall $96.63 \%$ had NCD risk factors, among them $30.90 \%$ had two risk factors and $50.26 \%$ had 3 or more risk factors. Overall prevalence of smoking was 36.8\%, among them $20.5 \%$ were current smoker. Mean duration of smoking was 16.71 pack year. Among the smoker majority were male ( $73.3 \%$ vs $26.7 \%) .33 .1 \%$ of the study population used to take smokeless tobacco, mean duration of intake was 13.54 years. Unlike smoking smokeless tobacco consumption was more in female (65.3\% vs $34.7 \%)$. In our study none of the study population had history of intake of alcohol. $34.3 \%$ of the study population used to take added salt during meal, majority of them was female (63.9\%). Among the survey population only $14.3 \%$ used to take vegetables 7 days/week and majority $72.5 \%$ of the people took vegetables $2-4$ days/ week. $90.2 \%$ people used to take red meat (beef and mutton). Among them more than half of the people 53.1\% used to take red meat once in a week, $22.2 \%$ took $2-4$ days/week and $14.6 \%$ of the people took meat once in a month. $98.3 \%$ patient used to take chicken. $51 \%$ used to take chicken once in a week, $39 \%$ took $2-4$ days/week and $7.6 \%$ of the people took meat once in a month. $75.8 \%$ of the study people used to take battle nut, among them $23.3 \%$ took every day in a week.

$29.7 \%$ (106) of the female used hormonal contraceptives (in the form of OCP, injectable and depot preparation), among them majority were used OCP (17.1\%). Overall 32.6\% (116) people were physically inactive and $6.7 \%(24)$ had sedentary lifestyle. Regular exercise (30 minutes of walking) was found in only $21.9 \%$ of the people. Based on body mass index $18.8 \%$ (67) of the population were underweight, $61.5 \%$ (219) were normal weight, $14.3 \%$ (51) were overweight and 5.3\% (19) were obese. $66.57 \%$ of the people had central obesity, out of them $14.88 \%$ were male and $51.68 \%$ were female.
Mean blood pressure was systolic $130.21 \mathrm{~mm}$ of $\mathrm{Hg}$ and diastolic $81.28 \mathrm{~mm}$ of $\mathrm{Hg}$. Among the study population $28.9 \%$ (103) were hypertensive, 6.17\% (22) were known hypertensive and $22.75 \%$ (81) were newly diagnosed and $48.3 \%$ were prehypertensive. Among the hypertensive $69.9 \%$ were female. Mean duration of hypertension was 4 years. Among the known hypertensive $72.7 \%$ (16) used to take antihypertensive drug regularly and blood pressure was controlled in only $27.3 \%$ (6). Mean blood glucose was 6.35 (mmol/L. Prevalence of diabetes was $4.77 \%$ (17), among them previously diagnosed $2.24 \%$ (8), newly diagnosed (on the basis of RBS $11 \mathrm{mmol} / \mathrm{l}$ or more) $2.52 \%$ (9). Among the diabetic $47.05 \%$ (8) were male and $52.95 \%$ (9) were female. Among the known diabetic mean duration was 4.12 years and $62.5 \%$ (5) of the patients used to take the antidiabetic drug regularly.

\section{Discussion:}

In our study we were able to collect data of 356 adult people of both sexes, response rate was intermediate. Because we have surveyed family of 200 students, so at least we had to collect 2 adults from each family. Though we have ensured the family on the previous day of our visit via phone call and to visit to collect data in between 5 to 8 PM so that they could present at that time. Poor response may be due to some of the earning member of the family use to go to work and some go out of the local area for their job purpose. For the same reasons female participants were more than male (66.3\% vs 33.7\%). In our study, prevalence of smoking was $36.8 \%$, which was higher than a study ${ }^{11}$ done in Rangpur $(23.9 \%)$ and also higher $(26.2 \%)$ than a data from nationwide study. ${ }^{10}$ This may be due to tobacco cultivation here, so tobacco products are available and cheap in this area. Though traditionally smokeless tobacco (SLT) was not been emphasized for its harmful health effect in Bangladesh, it is 
considered to have equal potential to impair health and can lead to scores of chronic diseases. In our study, $33.1 \%$ of the study population used to take smokeless tobacco, our result is almost similar $(31.7 \%)$ found in other study ${ }^{10}$ done in Bangladesh. Unlike smoking, smokeless tobacco (SLT) consumption was more in female (65.3\% vs $34.7 \%)$.

Excessive salt intake is an important risk factor for developing hypertension. In our study $34.3 \%$ of the study population use to take added salt during meal, another study ${ }^{11}$ found $50 \%$ of the peoples used to take added salt. This may be due to the steps taken by the Government for reduction of NCD risk factors. Though a study ${ }^{10}$ has shown that vegetable consumption was particularly better in Bangladeshi population, our study found $72.5 \%$ of the people took vegetables 2-4 days/week, which is suboptimal. However we did not assess the amount of vegetables. Low physical activity is considered as an important predictor of many chronic diseases, most notably heart disease, stroke, obesity, type 2 diabetes, some types of cancers, and osteoporosis ${ }^{12}$. Beyond its role in the development of obesity, physical inactivity and associated poor cardio-respiratory fitness pose direct health risks ${ }^{13}$. The global estimate for prevalence of physical inactivity among adults is $17 \%{ }^{14}$ In our study physical inactivity was found in $32.6 \%$ of the people which is higher than previous studies $27 \% .^{10}$

Obesity is one of the important risk factor for hypertension. Friedman et $\mathrm{al}^{15}$ carried out a 6-year follow-up study on hypertension and obesity; and found that obesity and weight gain were clear precursors of hypertension. In our study obesity was found more than other study ${ }^{10}$ conducted in our country (5.3\% vs 3.6\%). Central obesity was found in our study $66.57 \%$, which was $53 \%$ in a community based study ${ }^{11}$ of this region. It is noteworthy that central obesity is a special characteristic of south Asian population in general. ${ }^{16}$ Waist circumference provides an indication about the central obesity and has been suggested to be a risk factor more specific to cardiovascular disease as visceral fat is considered as a predictor of morbidity and mortality.

Hypertension is a disease of its own as well as a risk factor for other major disease such as stroke, coronary heart disease, heart failure and renal insufficiency. It is very common in Bangladeshi people but its detection and treatment status is far from adequate. ${ }^{10}$ In our study $28.9 \%$ were hypertensive, Ratindra et $\mathrm{al}^{11}$ found even higher prevalence of hypertension in this region $33.3 \%$ in 2012. But this is much higher than the finding ${ }^{10}(17.8 \%)$ of a nationwide survey report of 2010. Control of hypertension is essential for ensuring cardiac, cerebral and renal health. In this regard rational intake of prescribed antihypertensive drug, where indicated, is mandatory. ${ }^{10}$ In a study ${ }^{17}$ in USA, blood pressure was control in $24 \%$ of all hypertensive's, in our study $72.7 \%$ used to take antihyperetnsive drug regularly and blood pressure was controlled in only $27.3 \%$. In our country prevalence of DM was $3.9 \%{ }^{10}$, our study has found almost similar findings $4.77 \%$, but among them $37.5 \%$ of the patients did not take the antidiabetic drug regularly. NCD risk factors are usually seen in clusters. In our study overall $96.63 \%$ had NCD risk factors, among them $30.90 \%$ had two risk factors and $50.26 \%$ had 3 or more risk factors. NCD risk factor survey ${ }^{10}-2010$ in Bangladesh found almost similar findings, where about $98.7 \%$ have at least one risk factor, $77.4 \%$ had two or more risk factors and $28.3 \%$ had 3 or more risk factors. An important difference was an increase of clustering of risk factors, 3 or more risk factors was increased from $28.3 \%$ to $50.26 \%$. NCD associated risk factors are largely modifiable. Therefore, by identifying and preventing the risk factors, NCDs such as coronary heart disease and stroke would be prevented by $80 \%$, cancer by $40 \%$ and type 2 diabetes by $90 \%$. In addition, one third of all cancers could be prevented by eating healthy food, maintaining normal weight and being physically active throughout the lifespan. ${ }^{18,19}$

\section{Conclusions:}

In our study, awareness of NCD is very low but high prevalence of NCD risk factors, which are modifiable. So, an appropriate intervention is needed to modify the risk factors and thus prevention of NCDs.

Conflict of interest: This study was funded by Bangladesh Society of Medicine.

\section{References:}

1. Non-communicable diseases; Fact sheet, Updated January 2015. Available from http://www.who.int/mediacentre/ factsheets/fs $355 / \mathrm{en} /$.

2. Lim SS, Vos T, Flaxman AD, Danaei G, Shibuya K, AdairRohani $\mathrm{H}$ et al. A comparative risk assessment of burden of disease and injury attributable to 67 risk factors and risk factor clusters in 21 regions, 1990-2010: a systematic analysis for the Global Burden of Disease Study 2010. Lancet, 2012;380(9859):2224-2260.

3. World Health Organization. WHO NCD Surveillance Strategy. Available at $<$ http://www.who.int/ncd_surveillance/strategy/ en/print.html $>$. accessed on 22 Oct 2010

4. World Health Organization. Global status report on noncommunicable diseases 2010. WHO Geneva 2011.

5. World Health Organization. Health profile of Bangladesh. WHO Bangladesh 2003. Available at http://www.whoban.org/ country_health_profile.html accessed on 22 Oct 2010. 
6. World Health Organization. World Health Report 2002: Reducing risks, promoting healthy life. WHO Geneva 2003.

7. Bangladesh Bureau of Statistics (2007) Statistical Pocketbook of Bangladesh 2007. Dhaka: Bangladesh Bureau of Statistics. Retrieved 13 May 2009 from http://www.bbs.gov.bd/ dataindex/pb_wb_page.pdf.

8. Health Bulletin, $2^{\text {nd }}$ edition, December, 2014; Management Information System, Directorate General of Health Services; available from http://www.dghs.gov.bd/images/docs/ Publicaations/HB 2014 2nd Edition 060115.pdf

9. Mondal RN, Alam MS, Haque MA, Jahan SMS, Azad AK, Hossain MZ, Rahman MMet al; Validity of verbal autopsy for assessment of causes of death in Bangladesh; European Academic Research, Vol. III, Issue 8/ November 2015.

10. NCD risk factor survey 2010 report published and disseminated published on $7^{\text {th }}$ August 2011http:// www.ban.searo.who.int/EN/Section31_295.htm.

11. Mondal RN, Haque MA, Jahan SMS, Azad AK, Rahman MM, Rani Moni et al. Prevalence and risk factors of hypertension in Rangpur, Bangladesh. World Heart J, 2013;5:91-100.

12. Chakravarthy MV, Joyner MJ, Booth FW. An obligation for primary care physicians to prescribe physical activity to sedentary patients to reduce the risk of chronic health conditions. Mayo clinic proceedings, 2002;77:165-73.

13. Stevens J, Evenson KR, Thomas O, Cai J, Thomas R. Associations of fitness and fatness with mortality in Russian and American men in the lipids research clinics study. International Journal of Obesity Related Metabolic Disorder 2004;28:1463-70

14. Mathers CD, Loncar D. Projection of global mortality and burden of disease from 2002 to 2030. Plos medicine, 2006;3:e442.

15. Friedman,Gary D, Ghannem H.- Precursor of Essential Hypertension, body weight, alcohol and salt use and parental history of Preventive Medicine 1988;17:387-400.

16. Yajnik CS, Yudkin JS. The Y-Y paradox. Lancet. 2004;363:163

17. Hypertension Study Group. Prevalence, awareness, treatment and control of hypertension among the elderly in Bangladesh and India: A multicentre study. Bull World Health Organ 2001;79:490-500.

18. World Health Organization. Preventing chronic diseases: a vital investment, WHO Geneva 2005.

19. World Health Organization. Mongolian STEPS Survey on the prevalence of non-communicable disease risk factors 2006. WHO Geneva 2007. 